\title{
Efeito do óleo de semente de uva prensado a frio nos marcadores bioquímicos e perfil inflamatório de ratos
}

\author{
Effect of cold pressed grape seed oil on rats' \\ biochemical markers and \\ inflammatory profile
}

Fernanda Branco SHINAGAWA'

Fernanda Carvalho de SANTANA ${ }^{1}$

Jorge MANCINI-FILHO'

RE S U M O

\section{Objetivo}

O objetivo deste trabalho foi avaliar o efeito do consumo crônico do óleo de semente de uva, obtido do mercado brasileiro, nos marcadores bioquímicos e inflamatórios de ratos saudáveis.

\section{Métodos}

Ratos Wistar, recém-desmamados e saudáveis, receberam por 65 dias óleo de semente de uva e soja em duas concentrações (3 e $6 \mathrm{~mL} / \mathrm{kg}$ de peso corporal). Os parâmetros avaliados foram a ingestão alimentar, peso corporal e dos tecidos hepático, cerebral e adiposo retroperitonial; neste último, foi ainda realizado o perfil de ácidos graxos. A análise dos parâmetros bioquímicos, peroxidação lipídica e perfil inflamatório através da quantificação das citocinas TNF- $\alpha$, IL-10 e IL-6 foi realizada no soro.

\section{Resultados}

O óleo de semente de uva, independentemente da dose administrada, promoveu maior acúmulo de gordura no tecido hepático e aumento nos níveis de peroxidação lipídica do soro. Verificou-se que, quando consumido na maior dose, houve maior incorporação do ácido graxo linoleico no tecido adiposo retroperitonial. Modificações nos parâmetros bioquímicos e inflamatórios séricos não foram observadas.

\section{Conclusão}

O consumo de óleo de semente de uva não provocou alterações metabólicas significantes em nenhuma das doses administradas ainda que se tenha observado uma elevação nos níveis de peroxidação lipídica sérica.

Palavras-chave: Ácido linoleico. Inflamação. Óleos.

1 Universidade de São Paulo, Faculdade de Ciências Farmacêuticas, Departamento de Alimentos e Nutrição Experimental. Av. Lineu Prestes, 580, Bloco 14, Butantã, 05508-000, São Paulo, Brasil. Correspondência para/Correspondence to: J MANCINI-FILHO.E-mail:<jmancini@usp.br>. 


\section{A B S T R A C T}

\section{Objective}

The aim of this study was to evaluate the effect of long term consumption of cold-pressed grape seed oil purchased in Brazil on the biochemical and inflammatory biomarkers of healthy rats.

\section{Methods}

Weaned and healthy Wistar rats received two concentrations (3 and $6 \mathrm{~mL} / \mathrm{kg}$ body weight) of grape seed and soy oil for 65 days. The parameters studied were food intake and body, liver, brain, and retroperitoneal adipose tissue weight. The fatty acid composition of the adipose tissue was also determined. Serum biochemical parameters, lipid peroxidation, and inflammatory profile were assessed, quantifying the cytokines tumor necrosis factor alpha, interleukin 10 and IL-6.

\section{Results}

Grape seed oil, regardless of dosage, promoted much fat accumulation on hepatic tissue and also increased serum lipid peroxidation. The highest dosage promoted the greatest incorporation of polyunsaturated fatty acids in the retroperitoneal adipose tissue. The biochemical parameters and serum inflammatory markers did not change.

\section{Conclusion}

Grape seed oil did not promote significant metabolic changes at either concentration but increased serum lipid peroxidation.

Keywords: Linoleic acid. Inflammation. Vegetable oil.

\section{N T R O D U ÇÃ O}

Diversas avaliações científicas demonstram que existe evidente correlação entre o consumo de óleos vegetais e funções benéficas e/ou deletérias ao organismo, dentre elas podemos citar a quantidade de lipídeos consumida, o seu tipo (saturada, monoinsaturada e/ou polinsaturada) e a distribuição posicional (trans e conjugados) ${ }^{1}$.

Nos dias atuais, recomenda-se a substituição na dieta da gordura saturada por polinsaturada (Ácido Graxo Polinsaturado [AGPI]), no intuito de reduzir a incidência de doenças cardiovasculares². Essa substituição se dá principalmente pelo aumento do consumo de óleos vegetais como fonte lipídica, e, consequentemente, pelo aumento da ingestão dos ácidos graxos polinsaturados, destacando-se o linoleico (C18:2 n-6), que está normalmente presente nesses óleos.

O consumo exacerbado de uma dieta rica em ácidos AGPI, incluindo os da classe n-6, como o caso do ácido linoleico, pode levar a alterações metabólicas que podem propiciar quadros inflamatórios. Isso acontece devido à formação exa- gerada de eicosanóides proinflamatórios, como as prostaglandinas e leucotrienos ${ }^{3}$.

O efeito adverso ocasionado pela elevada ingestão de AGPI também pode ser um aumento de produtos intermediários, como peróxidos e aldeídos, o que pode acarretar danos localizados nas membranas celulares, formação de Espécies Reativas de Oxigênio (ERO), oxidação de lipídeos de membrana, proteínas, enzimas, carboidratos e Deoxyribonucleic Acid (DNA), prejudicando o equilíbrio e gerando o estresse oxidativo ou danos oxidativos $^{4}$, e consequentemente, um quadro inflamatório no organismo humano e animal ${ }^{5}$.

Com isso, verifica-se muitas controvérsias sobre o efeito do consumo de AGPI no organismo humano e animal. Asadi et al. ${ }^{6}$ mostraram que a administração com dietas ricas em óleo de milho resultou em efeito deletério nos níveis de colesterol sérico. O mesmo grupo de estudo, dois anos mais tarde, investigou também o efeito com opcional ingestão de óleos vegetais durante dez semanas em ratos da linhagem Wistar, utilizando diferentes óleos vegetais, como canola, milho, óleo de uva e um derivado láctico (iogurte). Os 
autores verificaram uma significativa diminuição nos níveis de triacilgliceróis no fígado após ingestão opcional de óleo de uva e de iogurte em relação a outros óleos e ao grupo-controle tratado com água ${ }^{7}$.

O óleo de semente de uva prensado a frio apresenta elevado teor de ácido graxo essencial, nomeadamente o ácido linoleico, e também está presente um significativo teor de vitamina $\mathrm{E}$ em sua composição. A vitamina E possui conhecidamente ação protetora aos radicais livres e propriedade antitumoral devido seu potencial antioxidante ${ }^{8}$, surgindo dessa forma o interesse na investigação do efeito no consumo desse óleo no sentido de tê-lo como uma opção de consumo na alimentação humana.

Dentro desses princípios, somando-se os aspectos ambientais, o presente estudo objetivou avaliar os efeitos no consumo do óleo de semente de uva, prensado a frio, existente no mercado brasileiro, oriundo do resíduo agroindustrial e gerado por uma indústria brasileira produtora de vinhos e sucos.

\section{MÉ T O D O S}

\section{Material}

O óleo de semente de uva foi adquirido no ano de 2013 diretamente de uma empresa beneficiadora, situada na região de Antônio Prado, no Estado do Rio Grande do Sul. O óleo foi extraído por prensagem a frio das sementes de uva das variedades Isabel, Merlot e Niágara. A amostra foi mantida por 60 dias a $-18^{\circ} \mathrm{C}$ e encaminhada para o Laboratório de Lípides, Universidade de São Paulo (USP).

\section{Perfil de ácidos graxos do óleo}

A determinação do perfil de ácidos graxos foi realizada submetendo a amostra à metilação segundo método $\mathrm{Ce} 2-66^{\circ} \mathrm{e}$, em seguida, à determinação da composição de ácidos graxos por cromatografia de fase gasosa, método Ce 1-62 ${ }^{10}$.
As condições cromatográficas para análise foram: coluna cromatográfica de sílica fundida SP-2560 (biscianopropil polisiloxana) de $100 \mathrm{~m}$ e $0,25 \mathrm{~mm}$, programação de temperatura da coluna: isotérmico a $140^{\circ} \mathrm{C} / 5$ minutos e então aquecimento a $4^{\circ} \mathrm{C}$ /minutos até $240^{\circ} \mathrm{C}$, permanecendo nessa temperatura por 20 minutos, temperatura do vaporizador: $250^{\circ} \mathrm{C}$, temperatura de detector: $260^{\circ} \mathrm{C}$, gás de arraste hélio com vazão de $1 \mathrm{~mL} /$ minutos e razão de divisão da amostra a $1 / 100$.

A quantificação dos diferentes ácidos graxos foi realizada por comparação entre os tempos de retenção das amostras e os padrões de referência. Os resultados foram expressos pela porcentagem direta de área de cada pico dos ácidos graxos identificados.

\section{Ensaio biológico}

O experimento foi aprovado pela Comissão de Ética em Uso de Animal (Protocolo CEUA FCF/332) da Faculdade de Ciências Farmacêuticas da USP, estando de acordo com os princípios éticos para a experimentação animal adotados pelo Colégio Brasileiro de Experimentação Animal (COBEA).

Ratos (Rattus novergicus, var. albinus) machos da linhagem Wistar, recém-desmamados, com um mês de vida e peso inicial médio de $53,77 \pm 0,06 \mathrm{~g}$, foram distribuídos em cinco grupos experimentais com oito animais cada um: grupo-controle (água), dois grupos recebendo diariamente óleo de uva $(U)$ em duas concentrações (3 $\mathrm{mL} / \mathrm{kg}$ e $6 \mathrm{~mL} / \mathrm{kg}$ ) e dois grupos isocalóricos recebendo óleo de Soja (S) nas mesmas concentrações do óleo de uva. O tratamento foi realizado diariamente via intubação orogástrica (gavage).

Durante 65 dias de experimento, os animais tiveram acesso livre à água e à ração comercial peletizada irradiada e foram mantidos em gaiolas de propileno com condições ambientais controladas: temperatura entre $22 \pm 20^{\circ} \mathrm{C}$, ciclo 
claro/escuro de 12 horas, umidade relativa de $55 \%$, trocas de ar de 15 a 20 trocas/hora.

A pesagem dos animais, assim como a da ração, foi realizada duas vezes por semana. O cálculo do Coeficiente de Eficácia Alimentar (CEA) foi obtido a partir da razão do ganho de peso do animal pelo consumo de ração.

\section{Composição centesimal da ração}

Para determinação dos teores de proteínas, lipídios, carboidratos e cinzas utilizaram-se os procedimentos descritos na American Oil Chemists' Society (AOAC) ${ }^{10}$. As proteínas totais (fator de conversão=6,25) foram estimadas pela técnica micro-Kjeldahl. Os lipídios totais foram determinados após extração de uma massa conhecida da amostra com éter de etílico, utilizando o aparelho de Soxhlet. As cinzas foram determinadas por incineração a $550 \pm 15^{\circ} \mathrm{C}$ em forno mufla. Os carboidratos totais foram determinados pelo cálculo da diferença entre $100 \mathrm{~g}$ do alimento e a soma total dos valores encontrados para umidade, proteínas, lipídios e cinzas. Os dados foram expressos em g por $100 \mathrm{~g}$ de amostra seca.

A análise do perfil de ácidos graxos da ração comercial peletizada irradiada foi baseada no método de extração dos lípides e derivatização segundo método $996.06^{10}$ com uso do triglicerídeo do ácido graxo tridecanoico (C13:0) como padrão interno. Foram utilizados os fatores de resposta teóricos do Flame Ionization Detector (FID, Detector de Ionização de Chama), do método Ce 1h-05 da $\mathrm{AOCS}^{9}$ e determinação da composição de ácidos graxos por cromatografia de fase gasosa, método Ce 1-629. Os resultados foram expressos em g de $A G$ por $100 \mathrm{~g}$ de ração e a soma total dos AG saturados, monoinsaturados e polinsaturados expressos em porcentagem de gordura total na ração (Tabela 1).

\section{Teste oral de tolerância à glicose}

No $55^{\circ}$ dia de tratamento, os animais passaram por jejum de 6 horas e foram submetidos
Tabela 1. Composição centesimal da ração comercial utilizada no experimento. Departamento de Alimentos e Nutrição Experimental (Faculdade de Ciências Farmacêuticas/Universidade de São Paulo). São Paulo (SP), 2012-2014.

\begin{tabular}{lcc}
\hline \multirow{2}{*}{ Componentes } & \multicolumn{2}{c}{$(\mathrm{g} / 100 \mathrm{~g})$} \\
\cline { 2 - 3 } & Desvio-Padrão & Média \\
\hline Carboidratos & 49,10 & $\pm 1,18$ \\
Proteínas & 27,52 & $\pm 1,01$ \\
Fibras totais & 11,86 & $\pm 2,11$ \\
Cinzas & 18,54 & $\pm 0,23$ \\
Gorduras totais* & 4,83 & $\pm 0,19$ \\
14:0 & 0,02 & $\pm 0,00$ \\
16:0 & 0,68 & $\pm 0,01$ \\
$18: 0$ & 0,16 & $\pm 0,01$ \\
18:1 (n-9) & 1,13 & $\pm 0,05$ \\
18:2 (n-6) & 2,45 & $\pm 0,10$ \\
$18: 3$ (n-3) & 0,19 & $\pm 0,01$ \\
Saturados & 0,86 & $\pm 0,02$ \\
Monoinsaturados & 1,13 & $\pm 0,05$ \\
Polinsaturados & 2,63 & $\pm 0,11$ \\
\hline
\end{tabular}

Nota: Resultados expressos em Média \pm Desvio-Padrão $(n=3)$.

*A determinação de gordura foi calculada a partir do triglicerídeo do ácido tridecanóico, que foi utilizado como padrão interno.

ao Teste Oral de Tolerância à Glicose (TOTG) de acordo com Houde et al. ${ }^{11}$. Foi coletado o sangue da veia caudal (tempo 0), e, em seguida, administrada solução de dextrose $(2 \mathrm{~g} / \mathrm{kg}$ de peso corporal), via gavage, e coletado sangue nos tempos de 30, 60, 90 e 120 minutos. O teor de glicose foi obtido utilizando o glicosímetro Accu-Check Performa.

\section{Parâmetros bioquímicos séricos}

Foi realizada a quantificação da glicose, triacilgliceróis, colesterol total, Hight Density Lipoprotein (HDL, Lipoproteína de Alta Densidade) e a atividade das enzimas marcadoras de dano hepático - Alanina Amino Transferase (ALT) e Aspartato Amino Transferase (AST). Essas análises foram realizadas em analisador bioquímico automático (LABMAX 240, versão 2.0) com os Kits

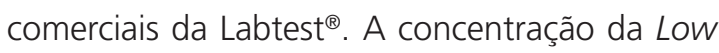
Density Lipoprotein (LDL, Lipoproteína de Baixa Densidade) foi estimada de acordo com a equação de Friedewald ${ }^{12}$. 


\section{Percentual de gordura tecidual}

Foi realizada a quantificação da gordura nos tecidos hepático e cerebral através da soma quantitativa dos ácidos graxos, seguindo a metodologia descrita na AOAC 996.06 ${ }^{10}$.

\section{Peroxidação lipídica}

A determinação da peroxidação lipídica no soro dos animais foi realizada através da medida da produção das Thiobarbituric Acid Reactive Substances (TBARS, Substâncias Reativas ao Ácido Tiobarbitúrico), utilizando-se o método descrito por Ohkawa et al. ${ }^{13}$. Os resultados foram expressos em nmol de equivalentes de 1,1',3,3'-Tetraetoxipropano (TEP) $\cdot \mathrm{mL}^{-1}$.

\section{Citocinas inflamatórias}

A quantificação dos marcadores inflamatórios - Tumor Necrosis Factor Alpha (TNF- $\alpha$, Fator de Necrose Tumoral Alfa) -, e Interleucina 6 (IL-6) e 10 (IL-10) - no soro dos animais foi realizada com a utilização dos Kits Milliplex, empregando a tecnologia Luminex ${ }^{\mathrm{TM}}$ XMAP. Os resultados foram expressos em pg. $\mathrm{mL}^{-1}$.

\section{Análise estatística dos dados}

Os resultados das análises foram inicialmente submetidos ao teste de Hartley para avaliação quanto à homogeneidade das variâncias. As amostras não homogêneas $\left(P_{\text {Hartley }}<0,05\right)$ foram submetidas ao teste de Box-Cox para sua transformação ${ }^{14}$. Em seguida, todos os dados foram submetidos ao teste Análise de Variância (Anova) univariada, seguido do teste paramétrico de Tukey a 5\% de significância. Todas as análises foram realizadas em triplicata, sendo os resultados expressos pelo valor médio \pm Desvio-Padrão (DP). Foi utilizado o programa Statistica 11 e software Prism 7.0 (GraphPad) para todas as análises estatísticas.

\section{RES U L T A D OS}

\section{Perfil de ácidos graxos do óleo de semente de uva}

Ácidos graxos polinsaturados são majoritários $(72,50 \pm 0,32 \%)$ no óleo de semente de uva, sendo o ácido graxo essencial, representante da família n-6 - ácido linoleico $(72,12 \pm 0,31 \%)$, o mais abundante. Em seguida, foi encontrado o ácido graxo monoinsaturado da família n-9 - ácido oleico com média de 16,70 $\pm 0,07 \%$. Proporções similares no perfil do óleo de soja também foram verificadas, no entanto com menor concentração do ácido graxo linoleico $(52,94 \pm 0,15 \%)$, conforme apresentado na Tabela 2.

\section{Avaliação alimentar e ponderal total e tecidual}

Ao início do tratamento, os animais $(n=8)$ dos cinco grupos experimentais apresentaram média similar $(p<0,01)$ de peso corporal $(53,77 \pm 0,06)$. Após o tratamento de 65 dias, não foi verificado diferença estatística no ganho de

Tabela 2. Perfil de ácidos graxos (\%) presentes no óleo de semente de uva e soja. Departamento de Alimentos e Nutrição Experimental (Faculdade de Ciências Farmacêuticas/Universidade de São Paulo). São Paulo (SP), 2012-2014.

\begin{tabular}{lrr}
\hline \multirow{2}{*}{ Ácidos graxos } & \multicolumn{3}{c}{$\%$ ácidos graxos } \\
\cline { 2 - 4 } & \multicolumn{1}{c}{ Óleo de Uva } & Óleo de Soja \\
\hline C16:0 & $6,79 \pm 0,01$ & $10,65 \pm 0,03$ \\
C16:1 & $0,14 \pm 0,05$ & n.d. \pm n.d. \\
C18:0 & $3,62 \pm 0,02$ & $3,34 \pm 0,01$ \\
C18:1 c (n-9) & $16,70 \pm 0,07$ & $22,31 \pm 0,08$ \\
C18:2 c (n-6) & $72,12 \pm 0,31$ & $52,94 \pm 0,15$ \\
C18:3 (n-3) & $0,38 \pm 0,01$ & n.d. \pm n.d. \\
C20:1 (n-9) & $0,19 \pm 0,06$ & $6,16 \pm 0,02$ \\
Saturados & $10,41 \pm 0,03$ & $13,99 \pm 0,04$ \\
Monoinsaturados & $17,03 \pm 0,18$ & $28,47 \pm 0,10$ \\
Polinsaturados & $72,50 \pm 0,32$ & $52,94 \pm 0,15$ \\
\hline
\end{tabular}

Nota: Resultados expressos em média \pm desvio-padrão $(n=3), p$-valor (Teste de Tukey). 
peso total entre os grupos tratados e o controle. Entretanto, a maior dose administrada ( $6 \mathrm{~mL} / \mathrm{kg}$ ), independentemente do óleo utilizado, foi capaz de induzir ao menor consumo diário de ração, refletindo, assim, em maiores valores do CEA, o qual está relacionado com o aporte suplementar dos óleos de soja e uva.

O peso final dos tecidos hepático e cerebral não foi alterado pelo consumo dos óleos estudados, porém verificou-se um armazenamento mais expressivo de gordura no tecido hepático, de maneira não dose dependente e significativa estatisticamente no consumo de óleo de uva, em comparação ao grupo-controle. No tecido cerebral, verificou-se que o consumo de óleo de uva não alterou a percentagem de gordura e que menor quantidade foi quantificada ao consumo de óleo de soja, independentemente da dose (Tabela 3).

\section{Análise da gordura total e do perfil de ácidos graxos do tecido adiposo retroperitonial}

Dos ácidos graxos saturados quantificados no tecido, os ácidos graxos palmítico (C16:0), margárico (C17:0) e esteárico (C18:0) não sofreram modificação com o tratamento, quando comparados ao controle. O ácido graxo mirístico (C14:0) foi menos incorporado ao tecido adiposo dos

Tabela 3. Efeito da dieta nos parâmetros de crescimento e nos parâmetros bioquímicos séricos de ratos Wistar alimentados com óleo de uva e soja. Departamento de Alimentos e Nutrição Experimental (Faculdade de Ciências Farmacêuticas/Universidade de São Paulo). São Paulo (SP), 2012-2014.

\begin{tabular}{|c|c|c|c|c|c|}
\hline Parâmetros & C & S3 & S6 & U3 & U6 \\
\hline Ganho de peso & $265,46 \pm 28,93$ & $271,67 \pm 21,66$ & $259,53 \pm 26,14$ & $274,38 \pm 12,44$ & $272,12 \pm 16,66$ \\
\hline Consumo final (g/dia/animal) & $24,50 \pm 5,40^{a}$ & $22,80 \pm 4,20^{a b}$ & $20,90 \pm 4,30^{\mathbf{b}}$ & $23,50 \pm 4,60^{a b}$ & $21,10 \pm 3,40^{\mathbf{b}}$ \\
\hline CEA & $0,17 \pm 0.02^{b}$ & $0,19 \pm 0,01^{a b}$ & $0,20 \pm 0,02 a$ & $0,18 \pm 0,00^{a b}$ & $0,20 \pm 0,01^{a}$ \\
\hline \multicolumn{6}{|l|}{ Peso final dos tecidos } \\
\hline \multicolumn{6}{|l|}{ (g/100 g peso corporal) } \\
\hline Adiposo retroperitonial & $1,10 \pm 0,27^{\mathbf{b}}$ & $1,31 \pm 0,32^{\mathbf{b}}$ & $1,65 \pm \quad 0,21^{a}$ & $1,30 \pm 0,17^{\mathbf{b}}$ & $1,52 \pm 0,40^{a}$ \\
\hline Hepático & $3,06 \pm 0,22$ & $3,03 \pm 0,28$ & $3,18 \pm$ & $2,96 \pm 0,21$ & $3,12 \pm 0,14$ \\
\hline Cerebral & $0,56 \pm 0,06$ & $0,54 \pm 0,04$ & $0,55 \pm$ & $0,54 \pm 0,02$ & $0,54 \pm 0,04$ \\
\hline \multicolumn{6}{|l|}{$\begin{array}{l}\text { Porcentagem de gordura nos } \\
\text { tecidos (g/100 g tecido) }\end{array}$} \\
\hline Hepático & $3,99 \pm 0,73^{c}$ & $5,30 \pm 1,11 b c$ & $5,46 \pm 1,32^{\mathbf{b c}}$ & $5,80 \pm 1,11^{a b}$ & $5,57 \pm 0,91^{a b}$ \\
\hline Cerebral & $6,19 \pm 0,77$ & $5,04 \pm 0,36$ & $5,95 \pm 0,37$ & $5,71 \pm 0,55$ & $5,74 \pm 0,53$ \\
\hline \multicolumn{6}{|l|}{ Enzimas Dano Hepático } \\
\hline AST (U/L) & $320,00 \pm 78,68$ & $332,75 \pm 44,20$ & $305,71 \pm 68,70$ & $389,12 \pm 58,40$ & $320,29 \pm 75,90$ \\
\hline ALT (U/L) & $73,62 \pm 15,70$ & $70,63 \pm 7,46$ & $76,00 \pm 15,01$ & $76,13 \pm 10,55$ & $71,43 \pm 3,00$ \\
\hline \multicolumn{6}{|l|}{ Lipidograma } \\
\hline $\mathrm{COL}(\mathrm{mg} / \mathrm{dL})$ & $68,50 \pm 8,90$ & $74,50 \pm 2,90$ & $72,63 \pm$ & $80,00 \pm 11,20$ & $79,25 \pm 9,74$ \\
\hline TAG $(\mathrm{mg} / \mathrm{dL})$ & $60,38 \pm 17,34$ & $52,50 \pm 16,11$ & $62,88 \pm 21,59$ & $46,75 \pm 12,35$ & $59,00 \pm 12,78$ \\
\hline $\mathrm{HDL}(\mathrm{mg} / \mathrm{dL})$ & $31,14 \pm 5,34$ & $32,12 \pm 2,50$ & $33,87 \pm 2,70$ & $31,87 \pm 3,14$ & $34,00 \pm 4,28$ \\
\hline $\mathrm{LDL}(\mathrm{mg} / \mathrm{dL})$ & $31,26 \pm 6,02^{\mathrm{abc}}$ & $31,87 \pm 3,75^{a b c}$ & $26,17 \pm 7,93^{c}$ & $38,77 \pm 8,58^{a}$ & $33,45 \pm 6,75^{a b c}$ \\
\hline HDL/LDL & $0,96 \pm 0,18^{\mathbf{b}}$ & $1,02 \pm 0,18^{a b}$ & $1,41 \pm \quad 0,50^{\mathrm{a}}$ & $0,85 \pm 0,18^{\mathbf{b}}$ & $1,04 \pm 0,17^{a b}$ \\
\hline \multicolumn{6}{|l|}{ Glicemia } \\
\hline GLI (mg/dL) & $116,75 \pm 19,30$ & $123,38 \pm 26,40$ & $133,75 \pm 22,45$ & $111,50 \pm 13,27$ & $117,00 \pm 17,10$ \\
\hline TOTG (AUC) & $18181,13 \pm 1522,19$ & $18995,88 \pm 1440,85$ & $18210,25 \pm 701,68$ & $17712,38 \pm 942,64$ & $17803,38 \pm 1079,38$ \\
\hline
\end{tabular}

Nota: Resultados expressos em média \pm desvio-padrão ( $n=8 / g r u p o)$. Letras diferentes na mesma linha diferem estatisticamente entre si $(p \leq 0,05)$. C: Grupo-Controle; S: óleo de Soja (grupo isocalórico); U: óleo de semente de Uva (grupo tratado), nas concentrações 3 e $6 \mathrm{~mL} / \mathrm{kg}$. A dose em mL foi administrada através do cálculo em função do peso em kg de animal; CEA: Coeficiente de Eficácia Alimentar, representado pela razão entre o consumo (g/dia/animal) pela quantidade em calorias (kcal) ingerida diariamente por animal; AST: Aspartato Transferase; ALT: Alanina Transferase; COL: Colesterol Total; TAG: Triglicérides; HDL: Hight Density Lipoprotein; LDL: Low Density Lipoprotein. HDL: razão entre as High Density Lipoprotein; GLI: conteúdo de Glicose total; TOTG: Teste Oral de Tolerância à Glicose; AUC: Area Under the Curve. 
animais do grupo suplementado com óleo de uva na maior dose (U6); quanto ao ácido pentadecílico (C15:0), foi verificado o mesmo comportamento para todos os grupos tratados com óleo de uva e soja, independentemente da dose utilizada (Tabela 4).

Não foram observadas alterações na concentração na maioria dos ácidos graxos monoinsaturados, com exceção para o ácido graxo nervônico (C24:1, n-9), que foi encontrado em menor quantidade nos animais tratados com óleo de soja, grupos S3 e 56 e óleo de uva na maior concentração U6.

Foi observada para os AGPI uma redução significativa do teor do ácido $\alpha$-linolênico (C18:3, n-3) nos grupos tratados com óleo de uva, independentemente da dose, em relação aos grupos tratado com soja e controle. Um significativo aumento nos teores dos AGs linoleico do isômero cis (C18:2, n-6) foi observado nos animais do grupo U6. O tratamento com óleos vegetais interferiu ainda na incorporação do ácido graxo araquidônico $(C 20: 4, n-6)$ no grupo $S 6$, do ácido graxo 7,10,13,16,19-docosapentanóico (C22:5, n-3) nos grupos tratados com óleo de soja e U3 e do ácido graxo DHA (C22:6, n-3) nos grupos 56 e U3.

No entanto, não foi observada nenhuma alteração $(p>0,05)$ no teor de gordura total do tecido adiposo $(\mathrm{g} / 100 \mathrm{~g})$ nos grupos tratados

Tabela 4. Perfil de Ácidos Graxos (AG) no tecido adiposo de ratos tratados com óleo de Uva (U) e óleo de Soja (S) durante 65 dias. Departamento de Alimentos e Nutrição Experimental (Faculdade de Ciências Farmacêuticas/Universidade de São Paulo). São Paulo (SP), 2012-2014.

\begin{tabular}{|c|c|c|c|c|c|}
\hline Ácidos graxos & C & S3 & S6 & U3 & U6 \\
\hline \multicolumn{6}{|l|}{ Saturados } \\
\hline C 14:0 & $0,92 \pm 0,18^{a}$ & $0,67 \pm 0,18^{\mathrm{ab}}$ & $0,69 \pm 0,10^{a b}$ & $0,78 \pm 0,25^{a b}$ & $0,60 \pm 0,18^{\mathbf{b}}$ \\
\hline C 16:0 & $19,61 \pm 4,45$ & $15,87 \pm 3,94$ & $16,35 \pm 2,49$ & $16,96 \pm 4,70$ & $14,41 \pm 2,72$ \\
\hline C 17:0 & $0,23 \pm 0,06$ & $0,18 \pm 0,04$ & $0,18 \pm 0,04$ & $0,15 \pm 0,07$ & $0,19 \pm 0,03$ \\
\hline \multicolumn{6}{|l|}{ Monoinsaturados } \\
\hline C $16: 1$ & $2,73 \pm 1,00$ & $2,01 \pm 1,18$ & $2,27 \pm 0,57$ & $2,37 \pm 1,40$ & $1,66 \pm 0,71$ \\
\hline C 17:1 & $0,15 \pm 0,05$ & $0,09 \pm 0,06$ & $0,11 \pm 0,03$ & $0,09 \pm 0,06$ & $0,14 \pm 0,02$ \\
\hline C18:1 & $22,45 \pm 5,73$ & $21,23 \pm 5,73$ & $23,21 \pm 4,48$ & $20,50 \pm 5,85$ & $20,81 \pm 3,30$ \\
\hline$C 20: 1$ & $0,11 \pm 0,10$ & $0,12 \pm 0,06$ & $0,12 \pm 0,06$ & $0,13 \pm 0,09$ & $0,14 \pm 0,06$ \\
\hline C18:2 C & $39,60 \pm 1,26^{\mathbf{b}}$ & $34,28 \pm 7,12^{\mathbf{b}}$ & $43,63 \pm 1,02^{a b}$ & $45,38 \pm 1,51^{a b}$ & $57,83 \pm 7,00^{a}$ \\
\hline C18:3n-6 & $0,17 \pm 0,04$ & $0,18 \pm 0,04$ & $0,20 \pm 0,04$ & $0,14 \pm 0,10$ & $0,16 \pm 0,03$ \\
\hline C18:3 n-3 & $2,85 \pm 1,20^{a}$ & $3,31 \pm 1,76^{a}$ & $3,42 \pm 0,78^{a}$ & $1,94 \pm 0,50^{b}$ & $1,52 \pm 0,23^{\mathbf{b}}$ \\
\hline$C 20: 2$ & $0,41 \pm 0,09$ & $0,55 \pm 0,27$ & $0,36 \pm 0,15$ & $0,75 \pm 0,64$ & $0,37 \pm 0,10$ \\
\hline$C 20: 3 n-6$ & $0,16 \pm 0,03$ & $0,22 \pm 0,08$ & $0,17 \pm 0,07$ & $0,33 \pm 0,03$ & $0,19 \pm 0,06$ \\
\hline$c 20: 4 n-6$ & $1,14 \pm 0,28^{a}$ & $0,77 \pm 0,23^{\mathrm{ab}}$ & $0,72 \pm 0,19^{b}$ & $1,10 \pm 0,43^{a b}$ & $0,82 \pm 0,22^{\mathrm{ab}}$ \\
\hline$C 22: 5 n-3$ & $0,15 \pm 0,04^{a}$ & $0,11 \pm 0,03^{b}$ & $0,10 \pm 0,02^{b}$ & $0,07 \pm 0,03^{b}$ & n.d. \\
\hline$C 22: 6 n-3$ & $0,22 \pm 0,07^{a}$ & $0,13 \pm 0,09^{a b}$ & $0,11 \pm 0,06^{\mathbf{b}}$ & $0,11 \pm 0,09^{b}$ & n.d. \\
\hline \multicolumn{6}{|l|}{ Trans } \\
\hline
\end{tabular}

Nota: Resultados expressos em média \pm desvio-padrão ( $n=8 /$ grupo). A determinação de gordura foi calculada a partir do triglicerídeo do ácido tridecanóico, que foi utilizado como padrão interno. Letras diferentes na mesma linha diferem estatisticamente entre si $(p<0,05)$.

n.d.: não detectado; C: Grupo-Controle; S: óleo de Soja (grupo isocalórico); U: óleo de semente de Uva (grupo tratado), nas concentrações 3 e $6 \mathrm{~mL} / \mathrm{kg}$. A dose em $\mathrm{mL}$ foi administrada através do cálculo em função do peso em $\mathrm{kg}$ de animal. 
tanto com óleo de soja quanto de uva e no grupo-controle (Tabela 4).

\section{Parâmetros bioquímicos séricos}

Não foi verificada alteração entre os grupos tratados e o controle em relação à concentração plasmática das enzimas AST e ALT, glicemia, resposta ao teste de tolerância à glicose, colesterol total, triglicerídeos totais e HDL-colesterol (Tabela 3). Quanto à concentração de LDL-colesterol, o grupo tratado com a maior dose (6 mL/kg) de óleo de soja apresentou teor significativamente inferior ao do grupo tratado com

A

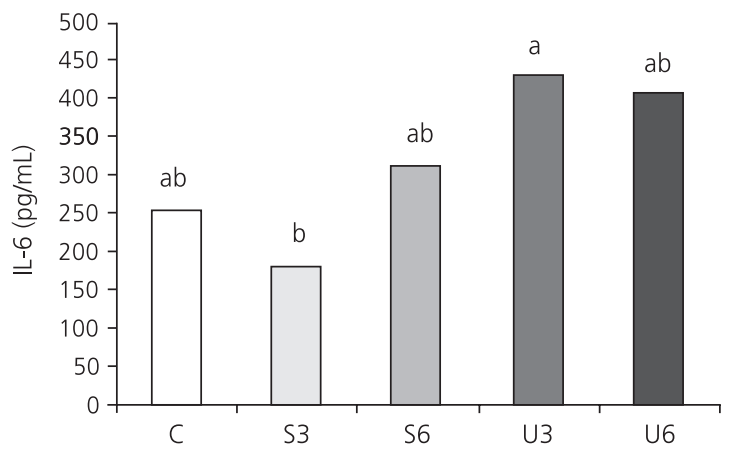

C

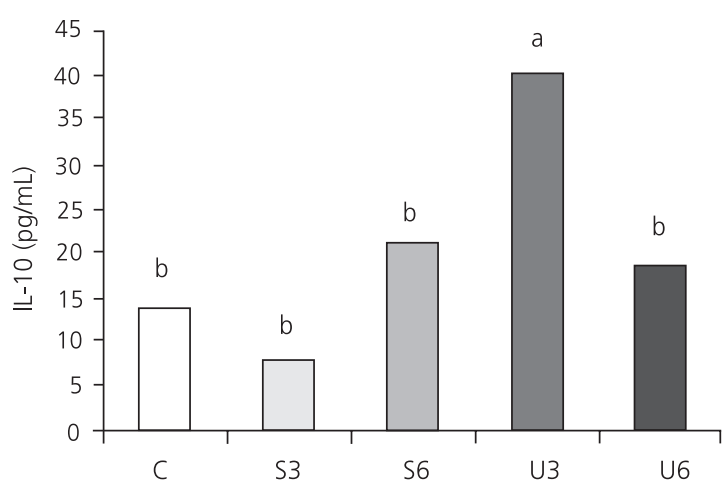

óleo de uva na menor dose (3 mL/kg), porém nenhum grupo tratado apresentou diferença estatística em relação ao grupo-controle. Esse fato interferiu no valor superior da razão HDL/LDL, verificado no grupo S6, quando comparado ao controle.

\section{Avaliação da peroxidação lipídica}

Pode-se observar que a susceptibilidade à peroxidação lipídica foi mantida nos animais tratados com óleo de soja, independentemente da dose, quando comparada ao grupo-controle $(p=0,01)$. Entretanto, foi observado aumento signi-

B

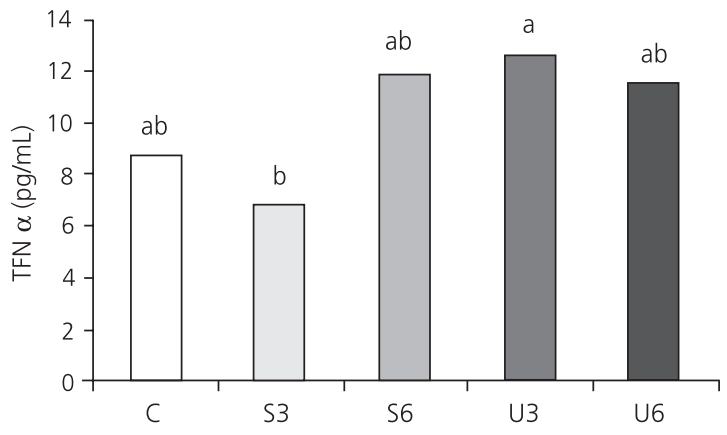

D

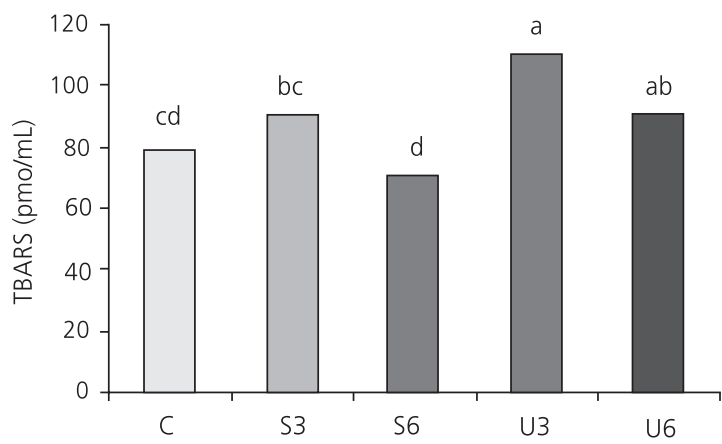

Figura 1. Citocinas Inflamatórias (a) IL-6 ( $n=6 / g r u p o)$, (b) TNF- $\alpha$ ( $n=6 / g r u p o$ ) e (c) IL-10 ( $n=6 / g r u p o$ ) e (d) Peroxidação lipídica pelo método TBARS (Thiobarbituric Acid Reactive Substances) ( $n=8 /$ grupo) no soro de ratos tratados com óleo de semente de Uva (U) e óleo de Soja (S) nas concentrações 3 mL/kg e 6 mL/kg em relação ao Grupo-Controle (C), durante 65 dias. Departamento de Alimentos e Nutrição Experimental (Faculdade de Ciências Farmacêuticas/Universidade de São Paulo). São Paulo (SP), 2012-2014.

Nota: Resultados expressos em média \pm standard error of mean ( $n=8 /$ grupo). Letras diferentes diferem estatisticamente entre si $(p \leq 0.05)$. 
ficativo de $63,98 \%$ desse valor nos animais tratados com o óleo de semente de uva, independentemente da dose $(p<0,05)$ (Figura 1).

\section{Perfil inflamatório sérico}

O consumo de óleo de soja e de semente de uva, independentemente da dose administrada, não promoveu aumento da concentração sérica das citocinas inflamatórias IL- 6 e TNF- $\alpha$. Verificou-se aumento significativo das concentrações de IL-10 nos plasma dos animais tratados com óleo de semente de uva, na dose de $3 \mathrm{~mL} / \mathrm{kg}$, quando comparados ao grupo-controle e demais grupos tratados com óleo de soja e semente de uva (Figura 1).

\section{I S C U S S Ã O}

A quantidade de ácido graxo poli-insaturado presente no óleo da semente de uva estudado, destacando-se ácido graxo linoleico, está de acordo com o verificado por outros autores ${ }^{15,16}$. Desse modo, sugere-se que todos os óleos de uva, independentemente da região de origem e mesmo quando submetidos ao refino ou extraído a frio, apresentam teor de ácido linoleico muito próximo ao preconizado pela legislação internacional, que corresponde à faixa entre 58,00-78,00\% ${ }^{17}$.

Os animais do grupo-controle consumiram uma dieta com valor total de $4,83 \%$ de gordura na ração, constituída majoritariamente por óleo de milho. Considerando que os animais consomem uma média de $20 \mathrm{~g}$ de ração por dia, os animais suplementados na maior dose de óleo de soja e semente de uva ( $6 \mathrm{~mL} / \mathrm{kg}$ ) atingiram uma porcentagem de lipídeos na dieta de aproximadamente $9,00 \%$, o que correspondeu a $21,63 \%$ de aporte energético em gordura. Para os animais suplementados na menor dose $(3 \mathrm{~mL} / \mathrm{kg})$, esse valor foi aproximado de $6,00 \%$ (16,06\% de energia). Dessa maneira, garantiu-se que a quantidade ofertada aos animais não caracterizou uma dieta como hiperlipídica, definida por uma dieta cujo conteúdo é igual ou superior a 30,00\% de energia proveniente da gordura, o que já ocasiona hipertrofia nos adipócitos ${ }^{18}$ e poderia causar um viés deletério ao organismo.

A suplementação com óleo de soja e semente de uva na maior dose, respectivamente os grupos $\mathrm{S} 6$ e U6, promoveu um menor consumo de ração por dia para os animais desse grupo, o que também refletiu em um maior valor de coeficiente de eficácia alimentar. Essa mudança no comportamento alimentar não foi significativa a ponto de interferir no ganho de peso final dos animais, em comparação ao grupo-controle. Resultados similares quanto ao ganho de peso foram encontrados para os animais submetidos à dieta com óleos de milho, algodão e suas respectivas misturas ${ }^{19}$ também para o óleo de peixe ${ }^{20}$ e óleo de soja ${ }^{21}$.

Apesar de não ter se verificado alteração no ganho de peso total dos animais em tratamento e no ganho de peso tecidual, independentemente do peso para os tecidos hepático e cerebral, verificou-se que os grupos de maiores doses, S6 e U6, promoveram um aumento de peso no tecido adiposo retroperitonial.

Tendo em vista que o consumo de óleo pode ter excedido a capacidade das lipoproteínas em secretá-las na circulação, foi verificado aumento do teor incorporado de gordura no tecido adiposo dos animais suplementados com óleo de uva, independentemente da dose suplementada, notadamente verificado para a incorporação do ácido graxo linoleico (C18:2) após tratamento com óleo de uva. Esse ácido graxo quando incorporado é metabolizado em decorrência de seu uso na cadeia dos eicosanoides, submetido à ação de enzimas elongases e dessaturases, formando assim o ácido araquidônico (C20:4) pela via n-6. Porém, não foi possível observar uma relação da maior incorporação de C18:2 com o aumento do C20:4 pelos animais.

Entretanto, foi possível verificar uma redução significativa nos teores do ácido $\gamma$-linolênico (C18:3, n-3) nos grupos tratados com ou em comparação tanto ao grupo tratado com soja 
como com o grupo-controle. Essa redução teve por consequência a redução de forma significativa dos ácidos C22:5 n-3 e C22:6 n-3 (DHA) nos grupos suplementados com óleo de uva, sugerindo que esse fato ocorra por serem AG resultantes da metabolização via cadeia de eicosanoides da família $n-3$.

O acúmulo de lipídios no tecido hepático sugere que ocorra uma tendência ao dano oxidativo e desestabilização da homeostasia no metabolismo glicídico e lipídico. Os resultados apresentados quanto ao aumento na porcentagem de gordura no tecido hepático e maior incor-poração do ácido linoleico no tecido adiposo retroperitonial demonstram a susceptibilidade desses animais à peroxidação de AGPI com efeito no aumento nos valores dos produtos finais da peroxidação lipídica.

Nesse sentido, os grupos tratados com óleo de semente de uva, U3 e U6, apresentaram maiores níveis de TBARS no soro quando comparados ao grupo-controle, confirmando, dessa forma, essa susceptibilidade. Esse comportamento também foi verificado por Tsuduki et al. ${ }^{22}$, que avaliaram o efeito da peroxidação lipídica em camundongos suplementados com óleo de girassol e de peixe e encontraram um aumento significativo nos valores de TBARS para os suplementados com óleo de peixe, devido aos altos teores de insaturações.

Entretanto, pode-se observar que não foram verificadas diferenças estatísticas significativas nas concentrações séricas das enzimas relacionadas ao dano hepático, indicando que a administração do óleo de uva não comprometeu o metabolismo hepático nesses animais durante todo o período de tratamento.

Em relação ao tecido cerebral, não foi observada alteração no peso final do tecido para os grupos tratados e o controle; esse resultado está de acordo com os resultados de Carver et al. ${ }^{23}$ em relação aos lipídeos cerebrais, os quais se apresentam mais resistentes a mudanças no teor de gordura do que outros tecidos.
A concentração e a composição dos ácidos graxos no plasma são influenciadas pela absorção da gordura dietética e/ou pela liberação dos ácidos graxos do tecido adiposo, e, com isso, o efeito da composição lipídica em dietas interfere de maneira significativa também nos parâmetros associados ao metabolismo de lipoproteínas ${ }^{24}$. Não foram observadas, porém, modificações nesses parâmetros com o consumo de óleo de soja e de semente de uva, independentemente da dose suplementada. Apenas o valor da razão HDL/LDL foi superior para os animais do grupo S6, indicando que o consumo desse óleo seja benéfico no sentido de prevenir doenças crônicas não transmissíveis.

Kim et al. ${ }^{25}$ investigaram o efeito de rações contendo diferentes fontes lipídicas, dentre elas o óleo de uva e soja, numa proporção similar ao deste trabalho (8 g/100 g de ração), por 32 dias, e verificaram que a suplementação com óleo de uva promoveu significativa redução do colesterol plasmático quando comparado ao óleo de soja. Esses autores sugerem que esse efeito benéfico foi resultado não apenas da presença de alto conteúdo de ácido linoleico (58-78\%), mas também do teor elevado de compostos minoritários, tais como tocotrienol (534-450 mg/kg) e polifenóis (10-34 mg).

Em relação à influência do consumo de óleos e gorduras nos parâmetros glicêmicos, Riccardi et al. ${ }^{26}$ mostraram os efeitos positivos e negativos na sensibilidade à insulina quando ocorre a mudança de 20 a $40 \%$ do total de energia em função da ingestão de gorduras totais na dieta. Assim como o total de lipídios consumido, o tipo de ácido graxo majoritário da dieta interfere na sensibilidade à insulina, como demonstrado por Buettner et al. ${ }^{27}$ para as dietas ricas em ácido oleico (n-3) ou em ácido linoleico (n-6), que resultam em melhoras na sensibilidade da insulina quando comparada a ácidos graxos saturados.

No presente trabalho, o excesso de C18:2, que foi administrado com as dietas suplementadas com o óleo de soja e de semente, não foi capaz de alterar a homeostase dos níveis plas- 
máticos de glicose em jejum e quando submetidas a uma sobrecarga de glicose (teste de tolerância oral a glicose). Outro parâmetro importante para avaliação quando se observa elevação na incorporação do C18:2 e nos valores da peroxidação lipídica é o perfil inflamatório sérico desses animais.

Exceto para as citocinas proinflamatórias, IL-6 e TNF- $\alpha$, observou-se aumento na concentração no soro dos animais tratados com óleo de uva na menor concentração para a citocina antiinflamatória IL-10. Corroborando esse fato, Li et al. ${ }^{28}$ compararam o efeito no soro de ratos submetidos a diferentes dietas acrescidas de $10 \%$ de cada óleo (sândalo, soja, oliva, girassol e linhaça) e também não verificaram alterações no teor da citocina TNF- $\alpha$, importante marcador envolvido em doenças inflamatórias.

Patterson et al. ${ }^{3}$ verificaram que o consumo elevado de dietas ricas em ácido graxo da família n-6, notoriamente o ácido linoleico, pode influenciar no teor de marcadores inflamatórios devido a seu potencial ligante aos receptores nucleares na célula e consequente capacidade em regular a expressão de genes ligados à inflamação.

O resultado encontrado no presente estudo mostra que a inclusão de óleo de semente de uva na dieta de ratos afetou funções biológicas, como o aumento da incorporação de ácido graxo no tecido adiposo e o nível de peroxidação lipídica sérica. A não alteração dos teores das citocinas proinflamatórias pode ser explicada, em parte, pela variabilidade nos resultados encontrados em cada animal, obtendo-se um desvio-padrão elevado.

\section{O N CLUSÃ O}

Com a maior incorporação de gordura no tecido hepático, e elevada incorporação do ácido linoleico, majoritário no óleo de uva, no tecido adiposo, pode-se identificar que, apesar da elevada carga lipídica oferecida aos animais, não foram observadas mudanças nos parâmetros bioquímicos e nos marcadores proinflamatórios avaliados no soro dos animais tratados com óleo de semente de uva. No entanto, verificou-se um aumento dos valores de TBARS, relacionados com o maior aporte dos ácidos graxos poli-insaturados, mais suscetíveis à oxidação.

\section{COLABORADORES}

FB SHINAGAWA colaborou na concepção do trabalho, desenho experimental, análise e interpretação dos dados e revisão do manuscrito; FC SANTANA colaborou na análise e interpretação dos dados e revisão do manuscrito; J MANCINI-FILHO colaborou na concepção do trabalho, desenho experimental, interpretação dos dados e revisão do manuscrito.

\section{REFERÊ NCIAS}

1. Dannenberger $D$, Nuernberg, $G$, Renne $U$, Nuernberg K, Langhammer M, Huber K, et al. High-fat diets rich in $\omega-3$ or $\omega-6$ polyunsaturated fatty acid have distinct effects on lipid profiles and lipid peroxidation in mice selected for either high body weight or leaness. Nutrition. 2013; 29(5):765-71. http://dx.doi.org/10.1016/j.nut.2012.10.010

2. Alvheim AR, Torstensen BE, Lin YH, Lillefosse, $H H$, Lock EJ, Madsen L, et al. Dietary linoleic acid elevates endogenous 2-arachidonoylglycerol and anandamide in Atlantic salmon (Salmo salar L.) and mice, and induces weight gain and inflammation in mice. J Br Nutr. 2013; 109(8):1508-17. http:// dx.doi.org/10.1017/S0007114512003364

3. Patterson E, Wall R, Fitzgerald GF, Ross RP, Stanton C. Health implications of high dietary omega-6 polynsaturated fatty acids. J Nutr Metabol. 2012; 2012(1):1-16. http://dx.doi.org/10.1155/2012/53 9426

4. Williams C, Buttriss J. Health benefits of Polyunsaturated Fatty Acids (PUFAs). Improving the fat content of foods. Boca Raton: CRC Press; 2006.

5. Covas Ml, Konstantinidou V, Fitó M. Olive oil and cardiovascular health. J Cardiovascular Pharmacol. 2009; 54(6):477-82. http://dx.doi.org/10.1097/FJC. 0b013e3181c5e7fd

6. Asadi F, Shahriari A, Pourkabir M, MacLaren R. Short and long-term effect of corn oil on serum lipid and lipoprotein and visceral abdominal fat pad parameters of rats. J Food Lipids. 2008; 15(1):68-80. http:// dx.doi.org/10.1111/j.1745-4522.2007.00103.x

7. Asadi F, Shahriari A, Charhardah-cheric M. Effect of long-term optional ingestion of canola oil, grape 
seed oil, corn oil and yogurt butter on serum, muscle and liver cholesterol status in rats. Food Chem Toxicol. 2010; 48(8-9):2454-57. http://dx. doi.org/10.1016/j.fct.2010.06.012

8. Fernandes L, Casal S, Cruz, R, Pereira JA, Ramalhos $E$. Seed oils of ten traditional Portuguese grape varieties with interesting chemical and antioxidant properties. Food Res Int. 2013; 50(1):161-66. http:// dx.doi.org/10.1016/j.foodres.2012.09.039

9. American Oil Chemists' Society. Official methods and recommended practices of the American Oil Chemists' Society. $5^{\text {th }}$ ed. Champaign: AOCS; 2004.

10. American Oil Chemists' Society. Association of official analytical chemists. Official methods of analysis, Arlington, Official Method. Champaign: AOCS; 2002.

11. Houde VP, Brûlé $S$, Festuccia WT, Blanchard PG, Bellmann $K$, Deshaies $Y$, et al. Chronic rapamycin treatment causes glucose intolerance and hyperlipidemia by upregulating hepatic gluconeogenesis and impairing lipid deposition in adipose tissue. Diabetes. 2010; 59(6):1338-48. http://dx.doi.org/10.2337/db09-1324

12. Fukuyama N, Homma K, Wakana N, Kudo K, Suyama A, Ohazama $H$, et al. Validation of the Friedewald equation for evaluation of plasma LDLcholesterol. J Clin Biochem Nutr. 2008; 43(1):1-5. http://dx.doi.org/10.3164/jcbn.2008036

13. Ohkawa H, Ohishi N, Yaoi K. Assay for lipid peroxides in animal tissues by thiobarbituric acid reaction. Anal Biochem. 1979; 95(2):351-58. http:// dx.doi.org/10.1016/0003-2697(79)90738-3

14. Box GEP, Cox DR. An analysis of transformations. J Royal Statistical Soc. 1964; 26(2):211-52.

15. Crews $C$, Hough $P$, Godward J, Brereton P, Lees $M$, Guiet $S$, et al. Quantitation of the main constituents of some authentic grape-seed oils of different origin. J Agricul Food Chem. 2006; 54(17):6261-65. http://dx.doi.org/10.1021/jf060338y

16. Rockenbach II, Rodrigues E, Gonzaga LV, Fett R. Fatty acid composition of grape (Vitis vinifera L. and Vitis labrusca L.) seed oil. Braz J Food Technol. 2010; III SSA:23-6.

17. Codex alimentarius. Codex standart for named vegetable oils. Codex STAN 210-1999. 2001 [cited 2013 Dec 15]. Available from: http://www.codex alimentarius.org/input/download/standards/336/ CXS_210e.pdf

18. Hariri N, Thibault L. High-fat diet-induced obesity in animal models. Nutr Res Rev. 2010; 23(2):270-99. http://dx.doi.org/10.1017/S0954422410000168

19. Radcliffe JD, King CC, Czajka-Narins DM, Imrhan V. Serum and liver lipids in rats fed diets containing corn oil, cottonseed oil, or a mixture of corn and cottonseed oils. Plant Foods Human Nutr. 2001; 56(1):51-60. http://dx.doi.org/10.1023/A:1008 189503099

20. Hosomi R, Fukunaga K, Arai H, Kanda S, Nishiyama T, Yoshida M. Effect of combination of dietary fish protein and fish oil on lipid metabolism in rats. J Food Sci Technol. 2013; 50(2):266-274. http://dx. doi.org/10.1007/s13197-011-0343-y

21. Kawabata T, Shimoda K, Domon M, Hagiwara C, Takiwama M, Kagawa Y. Influences of stearidonic acid-enriched soybean oil on the blood and organ biochemical parameters in rats. Prostaglandins, Leukotrienes and Essential Fatty Acids. 2013; 88(2):179-84. http://dx.doi.org/10.1016/j.plefa. 2012.11.004

22. Tsuduki T, Honma T, Nakagawa K, Ikeda I. Miyazawa T. Long-term intake of fish oil increases oxidative stress and decreases lifespan in senescenceaccelerated mice. Nutrition. 2011; 27(3):334-37. http://dx.doi.org/10.1016/j.nut.2010.05.017

23. Carver JD, Benford VJ, Han B, Cantor AB. The relationship between age and the fatty acid composition of cerebral cortex and erythrocytes in human subjects. Brain Res Bull. 2001; 56(2):79-85. http://dx.doi.org/10.1016/S0361-9230(01)00551-2

24. Curi R, Pompéia C, Miyasaka CK, Procópio J. Entendendo a gordura: os ácidos graxos. Barueri: Manole; 2002.

25. Kim DJ, Jeon G, Sung J, Oh SK, Hong HC, Lee J. Effect of grape seed oil supplementation on plasma lipid profile in rats. Food Sci Biotechnol. 2010; 19(1):249-52. http://dx.doi.org/10.1007/s10068-0 $10-0035-9$

26. Riccardi G, Giacco R, Rivellese AA. Review: Dietary fat, insulin sensitivity and the metabolic syndrome. Clin Nutr. 2004; 23(4):447-56. http://dx.doi.org/ 10.1016/j.clnu.2004.02.006

27. Buettner R, Parhofer KG, Woenckhaus M, Wrede CE, Kunz-schughart LA, Scholmerich J, et al. Defining high-fat-diet rat models: Metabolic and molecular effects of different fat types. J Molecular Endocrinol. 2006; 36(3):485-501. http://dx.doi.org/ 10.1677/jme.1.01909

28. Li G, Singh A, Liu Y, Sunderland B, Li D. Comparative effects of sandalwood seed oil on fatty acid profiles and inflammatory factors in rats. Lipids. 2013; 48(2):105-13. http://dx.doi.org/10.1007/s11745-0 $12-3752-4$ 